\title{
Analysis of Polymorphism rs1042522 in TP53 Gene in the Mothers of Twins and of Singletons: A Population-Based Study in Rio Grande do Sul, Brazil
}

\author{
Ana C. Mardini, ${ }^{1,2}$ Fernanda S. Pereira, ${ }^{3}$ Lavínia Schuler-Faccini, ${ }^{1,4,5}$ and Ursula Matte ${ }^{1,3,5}$ \\ ${ }^{1}$ Postgraduation Program on Adolescent and Child Health, Universidade Federal do Rio Grande do Sul, Porto Alegre, \\ Brazil \\ ${ }^{2}$ Paternity Investigation Laboratory, Fundação Estadual de Produção e Pesquisa em Saúde, Porto Alegre, Brazil \\ ${ }^{3}$ Molecular Analysis and Protein Unit, Universidade Federal do Rio Grande do Sul, Porto Alegre, Brazil \\ ${ }^{4}$ Medical Genetics Service, Hospital de Clínicas de Porto Alegre, Universidade Federal do Rio Grande do Sul, Porto \\ Alegre, Brazil \\ ${ }^{5}$ Postgraduation Program in Genetics and Molecular Biology, Universidade Federal do Rio Grande do Sul, Porto Alegre, \\ Brazil
}

\begin{abstract}
Although the birth of twins has always attracted attention, there are no known genetic or environmental factors that can determine the birth of monozygotic (MZ) twins. And even for dizygotic (DZ) twins, genetic influences are not completely understood. A previous study from our group has shown that the $C$ allele of polymorphism rs 1042522 in the TP53 gene was more frequent in the mothers of twins than in the mothers of singletons in a small village in South Brazil. In order to clarify whether this was an isolated factor, we performed a population-based, observational case-control study. Samples were selected from a state-funded program of paternity investigation. Samples were considered cases when two of the children had the same date of birth, whereas controls were those samples in which at least two children were born in different dates. The first subsequent sample fulfilling control criteria was included after each case. From 2007 to 2013, 32,661 records were searched and 283 (0.9\%) twins were found (119 MZ and $164 \mathrm{DZ})$. Genotypic and allele frequencies were not different between mothers of twins or mothers of singletons. However, mothers of $\mathrm{MZ}$ twins showed a higher frequency of GG genotype and lower frequency of the $\mathrm{C}$ allele when compared to mothers of DZ twins. Also, the proportion of $M Z$ twins (42\%) was higher than usually reported (30\%). Finally, the proportion of twins found in this study seems to be more realistic, as this sample was allegedly not from users of assisted reproduction techniques.
\end{abstract}

Keywords: twins, mutation, rs1042522, TP53

\begin{abstract}
Although the birth of twins has always attracted attention, there are no known genetic or environmental factors that can determine the birth of monozygotic (MZ) twins. The existence of hereditary factors is suggested by familial aggregation, especially for dizygotic (DZ) twins. Although the genetic influences are not completely understood, recent evidence points to the involvement of genetic variants involved in gonadal response to FSH, such as FSHB and SMAD3 (Mbarek et al., 2016). However, the gene for DZ twinning has yet to be mapped in humans, and even the mode of inheritance is not known (Hoekstra et al., 2008). MZ twins, on the other hand, seem to happen by chance only, without influence of ethnicity, maternal age, parity, or nutritional state (Tong \& Short, 1998).
\end{abstract}

An increase in the incidence of DZ twins has been observed worldwide, especially due to the use of assisted reproduction and a residual effect of the prolonged use of contraceptives (Hall, 1996). In the United States, the twinning rate was stable at 32 per 1,000 live births in 2006 (Chauhan et al., 2010), although more recent data suggested figures

RECEIVED 3 March 2016; ACCEPTED 13 December 2016. First published online 9 February 2017.

ADDRESS For CORRESPONDENCE: Ana Mardini, Postgraduation Program on Adolescent and Child Health, Universidade Federal do Rio Grande do Sul, Av. Paulo Gama, 110 - Farroupilha, Porto Alegre - RS, 90040-060, Brazil. E-mail: anacarolm@terra.com.br 
of 16.9 per 1,000 in 2011 (Martin et al., 2012). In Europe, the twinning rate has wide variation across countries, ranging from 16.1 per 1,000 in England and Wales to 21.2 per 1,000 in France (Pison et al, 2015). In Brazil, data from 1995 to 1998 showed rates of 19.51 per 1,000 births for DZ twins, whereas the MZ twinning rate was of 4.5 per 1,000 . This latter number is similar to the 4.1 per 1,000 previously described in the country (Colletto et al., 2001), and to figures reported elsewhere in the world (Macfarlane \& Blondel, 2003).

In Rio Grande do Sul (RS), the southernmost state of Brazil, there is a city called Candido Godói whose population presents a high rate of twinning, estimated at 15 per 1,000 births. Epidemiological data suggest a founder effect, dating from the late 19th century. Genetic analysis of TP53 and its regulators (MDM2, MDM4, and HAUSP) showed an association of polymorphism rs1042522 in TP53 and twinning in this population (Tagliani-Ribeiro et al., 2012). An additional study on twinning and TP53 was performed by Huang et al. (2015) in African Americans, but the association they found was with a different polymorphism (rs8079544). So far, there is no data on the association of polymorphism rs1042522 in TP53 and twinning in other regions, and it is debatable whether this is an isolated factor.

The Laboratory of Paternity Investigation (LPI) is a statebased laboratory in RS that receives samples from lowincome individuals for paternity investigation paid by the public defense system. On average, 400 cases from all over the state are analyzed per month. Considering that this population-based sample is presumably free of influences caused by fertility treatments, we decided to study the frequency of polymorphism rs1042522 in TP53 gene, and its relation to the birth of twins.

\section{Material and Methods}

This was a population-based, observational case-control study. Samples were selected from the LPI database of the period 2007-2013 from those where there was no doubt about maternity. Out of the 32,661 records, 583 were selected to fulfill criteria as cases or controls. Samples were considered cases when two of the children had the same date of birth, whereas controls were those samples in which at least two children were born in different dates. The first sample fulfilling control criteria was included after each case. For each sample, the following data was collected: mother's birth date and city of origin, and children's birth date.

DNA was extracted from archived FTA Cards (Whatman) using a commercial solution, according to the manufacturer's instruction (FTA Solution, Whatman). The presence of polymorphism rs1042522 in TP53 gene was determined in DNA samples from the mothers using TaqMan Assay C_2403545_10, as described by Tagliani-Ribeiro et al. (2012). Zygosity of same-sex twins was determined from data used in the panel of genetic markers for paternity investigation (CSF1PO, D13S317, D16S539, D18S51, D19S433, D21S11, D2S1338, D3S1358, D5S818, D7S820, D8S1179, FGA, TH01, TPOX, VWA, and amelogenin).

Statistical analysis using a chi-square test was performed in SPSS version 18.0, $p<.05$ considered significant. Approval from the local ethics committee was obtained without the need for informed consent as all data were treated anonymously.

\section{Results}

From January 2007 to December 2013, LPI performed 32,661 paternity investigations. Samples originated from 12 cities that were grouped into five regions (Figure 1). Out of these, $283(0.9 \%)$ were from mothers of twins. Therefore, the other 300 samples were included as controls (mothers of singletons). The mean age of mothers of twins at the time of twins' birth was 26.4 years $(\mathrm{MZ}=25.4$ and $\mathrm{DZ}=27.07)$, whereas the mean age of mothers of singletons at the time of the first child's birth was 24.5 years.

Among cases, the percentage of $\mathrm{MZ}$ twins was $42 \%$, differing from the estimated one-third referred to in the literature $(p=.04)$. The distribution of twin births as the percentage of $\mathrm{MZ}$ twins per region can be observed in Table 1. There was no statistically significant difference across regions regarding the percentage of twins $(p=.744)$. However, the Sierra and Northwest regions showed a smaller percentage of $\mathrm{MZ}$ twins compared to the other regions $(p=.0004)$, although with values closer to those described in the literature (30\%).

Data analysis of polymorphism rs1042522 in TP53 gene in the mothers of twins and of singletons did not show a statistically significant difference in genotypic (Table 2, $p=.371$ ) or allelic frequencies (Table $2, p=.187$ ).

However, when analyzed by zygosity, there was a difference in genotypic and allelic frequencies between mothers of DZ and MZ twins (Table 3). Genotype GG was more frequent than expected in the mothers of MZ twins $(p=.028)$, whereas the $C$ allele was diminished $(p=.016)$ in this same group of individuals. The odds ratio for allele $\mathrm{G}$ was 1.61 and for allele $\mathrm{C}$ it was 0.62 (SE 0.26).

\section{Discussion}

Although there is evidence of familial susceptibility for twinning, the genetic factors involved are unknown. Among studied candidate genes are growth differentiation factor 9 (GDF9) and bone morphogenetic protein 15 (BMP15), essential for normal human fertility and with a prominent role in follicle growth and ovulation (Moore et al., 2004). Recently, a genome-wide association study identified genetic risk variants for DZ twinning on a region near FSHB and SMAD3. These genes are involved in gonadal responsiveness to FSH and might contribute 


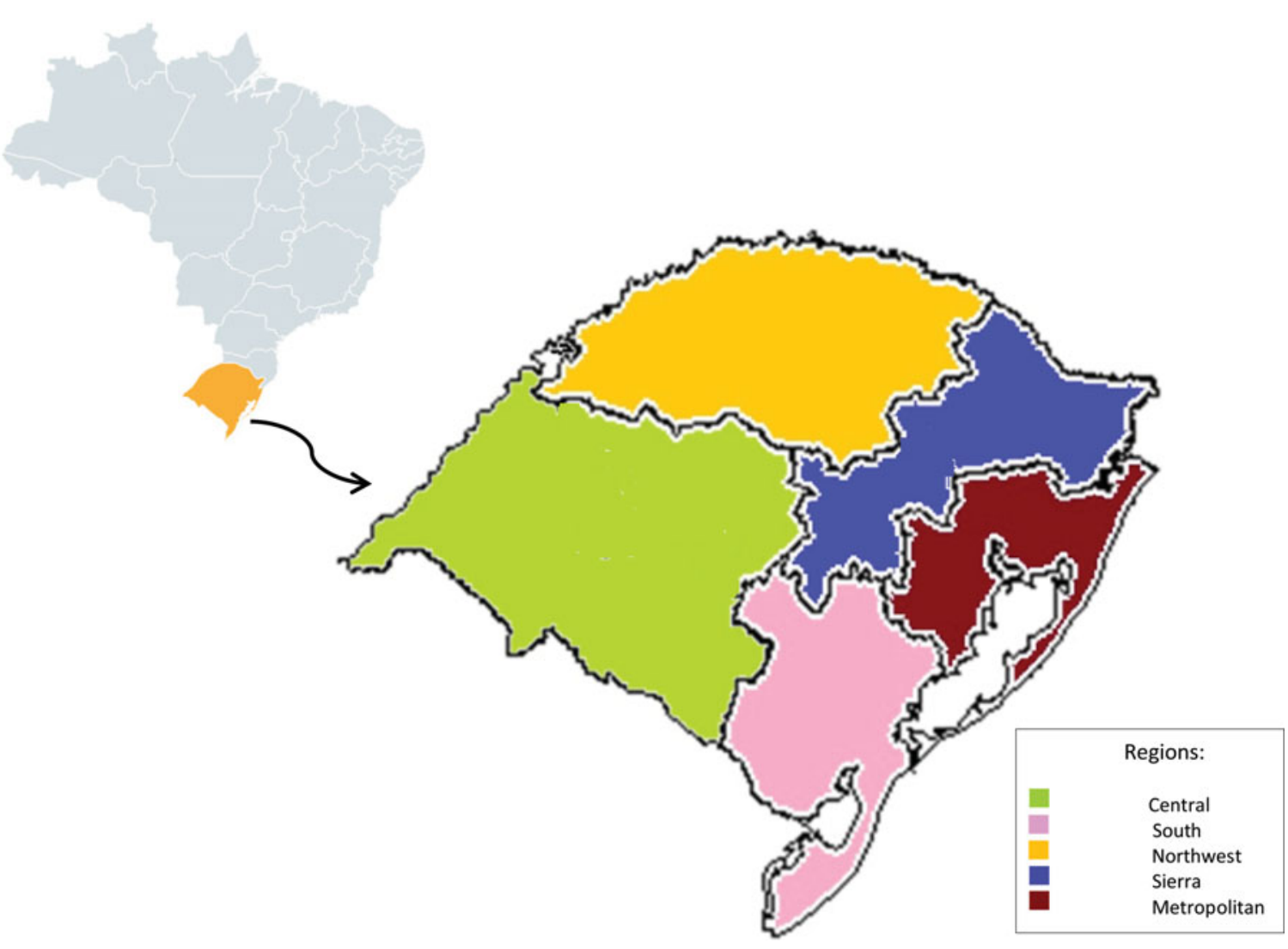

\section{FIGURE 1}

(Colour online) Regions of sample origin in Rio Grande do Sul (RS). The inset shows the location of RS in Brazil.

\section{TABLE 1}

Distribution of Twins (Both MZ and DZ) and of MZ Twins in Different Analyzed Regions

\begin{tabular}{lcc}
\hline Region & $\begin{array}{l}\text { Cases (MZ + DZ twins) } \\
n(\%)\end{array}$ & $\begin{array}{l}\text { MZ twins } \\
n(\%)\end{array}$ \\
\hline Metropolitan & $124(43.8)$ & $54(45.4)$ \\
Central & $33(11.7)$ & $18(15.1)$ \\
Sierra & $32(11,3)$ & $8(6.7)^{*}$ \\
Northwest & $60(21.2)$ & $21(17.6)^{*}$ \\
South & $34(12,0)$ & $18(15.1)$ \\
Total & $283(48)$ & $119(42)$ \\
\hline
\end{tabular}

Note: ${ }^{*} p=.0004$.

to crucial aspects of reproductive capacity (Mbarek et al., 2016).

A previous study from our group has shown that the C allele of polymorphism rs 1042522 in TP53 gene was more frequent in the mothers of twins than in the mothers of singletons in Candido Godoi, a small village in South Brazil (Tagliani-Ribeiro et al., 2012). However, the present study, analyzing a population-based sample, did not show a difference in allelic or genotypic frequencies between the mothers of twins and singletons. Nevertheless, a higher frequency of the $\mathrm{C}$ allele was found in the mothers of MZ twins as compared to the mothers of DZ twins. It is therefore, possible that the previous difference was in fact

\section{TABLE 2}

Distribution of Genotypic and Allelic Frequencies of Polymorphism rs1042522 in TP53 Gene in the Mothers of Twins $(n=285)$ and of singletons $(n=300)$

\begin{tabular}{lcc}
\hline & $\begin{array}{l}\text { Mothers of twins } \\
n(\%)\end{array}$ & $\begin{array}{l}\text { Mothers of singletons } \\
n(\%)\end{array}$ \\
\hline Genotype & $140(49.5)$ & $131(44.0)$ \\
GG & $116(41.0)$ & $136(45.0)$ \\
GC & $27(9.5)$ & $33(11.0)$ \\
CC & $396(69.80)$ & $398(66.3)$ \\
Allele & $172(30.20)$ & $202(33.7)$ \\
G & & \\
C & & \\
\hline
\end{tabular}

due to an excess of MZ twins' mothers in that sample. Unfortunately, zygosity was not performed by molecular studies in the previous work. Yet, there is the possibility that the data found in Candido Godoi by Tagliani-Ribeiro et al. (2012) reflected a founder effect that cannot be extended to other populations. Unfortunately, no data on ethnicity of our sample is available to tease out whether population stratification could be the basis of this difference. Nevertheless, data on genetic admixture of Latin American populations (Ruiz-Linares et al., 2014) showed a marked genetic homogeneity in the southernmost part of Brazil - the same origin of samples for the present study. In 


\section{TABLE 3}

Distribution of Genotypic and Allelic Frequencies of Polymorphism rs1042522 in TP53 Gene in Mothers of MZ $(n=119)$ and $D Z(n=166)$ Twins

\begin{tabular}{lcc}
\hline & $\begin{array}{l}\text { Mothers of MZ } \\
\text { twins } n(\%)\end{array}$ & $\begin{array}{l}\text { Mothers of DZ } \\
\text { twins } n(\%)\end{array}$ \\
\hline Genotype & \\
GG & $70(59.0)$ & $70(43.0)$ \\
GC & $40(33.5)$ & $76(46.0)$ \\
CC & $9(7.5)$ & $18(11.0)$ \\
Allele & & \\
G & $180(75.2)$ & $216(65.8)$ \\
C & $58(24.8)$ & $112(34.2)$ \\
\hline
\end{tabular}

addition, in the present work we could not exclude the presence of twins in the families of singleton mothers, as no data regarding other relatives were investigated (even though the previous birth of twins was ruled out).

Despite the lack of information in some relevant aspects, we chose to study this particular population as it can be considered free of influences caused by fertility treatments, since these are women using a public service for paternity investigation, limited to low income users, who do not have access to private fertility treatments. In our state, there is only one public service for assisted reproduction, and entrance to this program is difficult and limited to stable couples after assessment by a social worker. Therefore, we can assume that at least in its vast majority, this sample is free from influence of fertility treatments.

To the best of our knowledge, this is the second study to investigate the role of TP53 in twinning. Despite being extensively known for its role as a tumor suppressor (Levine et al., 2006), the TP53 gene also plays an important role in fertility. Forms of the p53 family (including p63 and p73) are involved in the maintenance of follicle pool, genomic integrity of germ cells, and blastocyst implantation (Hu et al., 2007). One of TP53's most studied variants is polymorphism rs1042522, which changes a cytosine into a guanine, thus replacing a proline with an arginine in residue 72 of the protein (p.P72R).

Studies in non-human primates suggest that the $\mathrm{C}$ allele (p.P72) is ancestral, although the G allele (p.R72) can reach frequencies over $0.5 \%$ in certain populations (Whibley et al., 2009). This change results in mild functional differences in the protein, and the variant p.P72 (C allele) is more efficient in initiating senescence and arresting the cell cycle, whereas the p.R72 (G allele) variant is more active in apoptosis induction and in suppressing cell transformation (Dumont et al., 2003). Kang et al. (2009) investigated the impact of such changes in the rates of embryo implant and successful pregnancy after in vitro fertilization. In young patients, p.P72 seems to be a risk factor for implantation failure. These data corroborate our study, as the $\mathrm{C}$ allele was under-represented in mothers of MZ twins.

Maternal age is a factor usually associated with twinning, although not with MZ twins (Aston et al., 2008). A positive association was described for DZ twins and maternal age by several groups (Lambalk et al., 1998). In the present study, no influence of maternal age was observed, even when comparing MZ and DZ mothers. This may be due to the sample type used in this study, formed mainly by young women having unplanned pregnancies. Therefore, a bias may be introduced, especially regarding DZ twins.

Also on this aspect, it is worth noticing the apparent excess of MZ twins in our sample. The reasons for this are not completely understood, because the risk factors for $\mathrm{MZ}$ twinning are not clear. Familial aggregation of MZ twins is rare and its cause may be due to a single gene related to the integrity of zona pellucida or the maintenance of cellcell connection (Hall, 1996). It is assumed that MZ twins comprise $30 \%$ of all twin births (Aston et al., 2008), but in the present sample they accounted for almost $42 \%$ of cases $(119 / 283)$.

Finally, the number of twin births found in this population-based sample (283) corresponds to only $0.9 \%$ of all paternity investigations analyzed at the LPI. Since the twinning rate for the state of RS is estimated to be $2 \%$ (DATASUS, 2015), one would expect that among the about 32,661 paternity investigations, 653 were of twins. However, the number found was almost half this value. Since there is no reason to suppose that mothers of twins seek state-paid paternity investigation in a different proportion compared to mothers of singletons, it may be inferred that the rate found in this study is more representative of the real twinning rate for RS, without the impact of assisted reproduction techniques. This hypothesis could be evaluated if data on the frequency of assisted reproduction among parents of twins were known or, if historical records of twin births were available for the state. Unfortunately, none of these figures are publicly available in Brazil. The oldest record of twin births available at DATASUS dates back to 1994 and indicates a proportion of $1.77 \%$ twin births in RS.

In brief, the present study investigated the frequency of polymorphism rs1042522 in TP53 gene in mothers of twins and singletons using a population-based sample of women seeking state-funded paternity investigations. Genotypic and allele frequencies were not different between groups, but mothers of MZ twins showed a higher frequency of GG genotype and lower frequency of the $\mathrm{C}$ allele when compared to mothers of DZ twins. Also, the proportion of $\mathrm{MZ}$ twins seems to be elevated in this sample and may represent a more realistic figure on twinning rates.

\section{References}

Aston, K. I., Peterson, C. M., \& Carrell, D. T. (2008). Monozygotic twinning associated with assisted reproductive technologies: A review. Reproduction, 136, 377-386.

Chauhan, S. P., Scardo J., A., Hayes, E., Abuhamad, A. Z., \& Berghella, V. (2010). Twins: prevalence, problems, and preterm births. American Journal of Obstetrics and Gynecology, 203, 305-315. 
Colletto, G. M. D. D., De Mattos Segre, C. A., \& Beiguelman, B. (2001). Twinning rate in a sample from a Brazilian hospital with a high standard of reproductive care. Sao Paulo Medical Journal, 119, 216-219.

DATASUS. (2010). Tecnologia da Informação a Serviço do SUS. Retrieved October 20, 2015, Retrieved from http://tabnet.datasus.gov.br/cgi/deftohtm.exe?sinasc/cnv/ nvuf.def.

Dumont, P., Leu, J. I., Della Pietra, A. C. III., George, D. L., \& Murphy, M. (2003). The codon 72 polymorphic variants of p53 have markedly different apoptotic potential. Nature Genetics, 33, 357-365.

Hall, J. G. (1996). Twins and twinning. American Journal of Medical Genetics, 204, 202-204.

Hoekstra, C., Zhao, Z.Z., Lambalk, C. B., Willemsen, G, Martin, N. G., Boomsma, D. I., \& Montgomery, G. W. (2008). Dizygotic twinning. Human Reproduction Update, 14, 37-47.

Hu, W., Feng, Z., Teresky, A. K., \& Levine, A. J. (2007). P53 regulates maternal reproduction through LIF. Nature, 450, 2-6.

Huang, H., Clancy, K. B. H., Burhance, C., Madrigal, L., \& Zhu, Y. (2015). Women who deliver twins are more likely to smoke and have high frequencies of specific SNPs: Results from a sample of African-American women who delivered pre-term, low birth weight babies. American Journal of Biology, 27, 605-612.

Kang, H., Feng, Z., Sun, Y., Atwal, G., Murphy, M. E., Rebbeck, T. R., ... Hu, W. (2009). Single-nucleotide polymorphisms in the P53 pathway regulate fertility in humans. Proceedings of the National Academy of Sciences of the United States of America, 106, 9761-9766.

Lambalk, C. B., De Koning, C. H., \& Braat, D. D. M. (1998). The endocrinology of dizygotic twinning in the human. Molecular And Cellular Endocrinology, 145, 97-102.

Levine, A. J., Feng, Z., Mak, T. W., You, H., \& Jin, S. (2006). Coordination and communication between the P53 and IgfI-Akt-Tor signal transduction pathways. Genes \& Development, 609, 267-275.
Macfarlane, A., \& Blondel, B. (2003). Demographic trends in Western European countries. In I. Blickstein \& L. G. Keith (Eds.), Multiple pregnancy: Epidemiology, gestation, and perinatal outcome (2nd ed., pp. 11-21). London. UK: Informa Healthcare.

Martin, J. A., Hamilton, A. B., Osterman, M. J. K., \& National Center for Health Statistics. (2012). Three decades of twin birth in the United States, 1980-2009. Hyattsville, MD: US Department of Health and Human Services, Centers for Disease Control and Prevention, National Center for Health Statistics.

Mbarek, H., Steinberg, S., Nyholt, D. R., Gordon, S. D., Miller, M. B., ... Boomsma, D. I. (2016). Identification of common genetic variants influencing spontaneous dizygotic twinning and female fertility. American Journal of Human Genetics, 98, 898-908.

Moore, R. K., Erickson, G. F., \& Shimasaki, S. (2004). Are BMP-15 and GDF-9 primary determinants of ovulation quota in mammals? Trends In Endocrinology And Metabolism, 15, 356-361.

Pison, G., Monden, C., \& Smits, J. (2015). Twinning rates in developed countries: Trends and explanations. Population and Development Review, 41, 629-649.

Ruiz-Linares, A., Adhikari, K., Acuña-Alonzo, V., QuintoSanchez, M., Jaramillo, C., Arias, , W., ... Gonzalez-José, R. (2014). Admixture in Latin America: Geographic structure, phenotypic diversity and self-perception of ancestry based on 7,342 individuals. PLoS Genetics, 10, e1004572.

Tagliani-Ribeiro, A., Paskulin, D. D., Oliveira, M., ZagonelOliveira, M., Longo, D., Ramallo, V., ... Matte, U. (2012). High twinning rate in Candido Godói: A new role for P53 in human fertility. Human Reproduction, 27, 28662871.

Tong, S., \& Short, R. V. (1998). Dizygotic twinning as a measure of human fertility. Human Reproduction, 13, 95-98.

Whibley, C., Pharoah, P. D. P., \& Hollstein, M. (2009). P53 Polymorphisms: Cancer implications. Nature Reviews Cancer, 9, 95-107. 